Departamento de Ciência e Tecnologia, Secretaria de Ciência, Tecnologia e Insumos Estratégicos, Ministério da Saúde

Correspondência | Correspondence:

Decit - Departamento de Ciência e Tecnologia

do Ministério da Saúde

Esplanada dos Ministérios

Bloco G sala 845

70058-900 Brasília, DF, Brasil

Texto de difusão técnico-científica do Ministério de Saúde.

\section{Evidências científicas: informação para a gestão}

\section{Scientific evidence: information management}

Após a implantação do Sistema Único de Saúde (SUS), a situação de saúde no Brasil passou por inegáveis avanços. Nos últimos 20 anos, houve aumento da cobertura populacional pelo Programa Saúde da Família, ampliação do número de consultas de pré-natal, bem como melhor controle das doenças imunopreveníveis, entre outras conquistas. No entanto, ainda persistem desigualdades entre as diversas regiões do País no que se refere à prestação de serviços de saúde. E, mais especificamente, um dos desafios relevantes na atualidade é a utilização de informações científicas na gestão do SUS.

Nesse contexto, é perceptível a necessidade de aperfeiçoar a capacidade nacional de produção e uso do conhecimento científico para auxiliar os gestores na tomada de decisão e nortear a formulação de políticas públicas em saúde. Com esse intuito, a Secretaria de Ciência, Tecnologia e Insumos Estratégicos do Ministério da Saúde, por meio do Departamento de Ciência e Tecnologia (Decit), apresentou projeto à Organização Pan-Americana da Saúde (OPAS) para adesão do Brasil à EVIPNet (Evidence-informed Policy Network), compondo uma rede colaborativa para elaboração e implementação de políticas baseadas em evidências científicas.

\section{USO SISTEMÁTICO DE EVIDÊNCIAS DE PESQUISA}

A EVIPNet surgiu em resposta à recomendação originada da reunião de ministros sobre pesquisa em saúde, realizada no México, em novembro de 2004, e referendada na 58 Assembléia Mundial da Saúde em Genebra, em maio de 2005. Esse projeto se baseia na necessidade de se estabelecer mecanismos para melhorar a utilização dos resultados de pesquisa no desenvolvimento de sistemas e políticas de saúde pública.
A EVIPNet tem por objetivo apoiar o desenvolvimento de políticas baseadas em evidências científicas, permitindo, também, o acesso permanente a elas. Essa iniciativa busca promover o uso sistemático de evidências de pesquisa no processo de elaboração e definição de políticas de saúde, por meio de parcerias entre gestores, representantes do controle social e pesquisadores.

A EVIPNet visa, então, difundir o uso compartilhado de conhecimentos científicos e sua aplicação, em formato e linguagem adequados aos gestores de saúde, seja na prática clínica, gestão dos sistemas de saúde, formulação de políticas públicas e cooperação técnica entre os países participantes.

Outro importante aspecto da EVIPNet é a contribuição para a adoção de métodos e estratégias inovadoras em saúde, atuando como um espaço de troca de informações e experiências entre os países e, internamente, entre os tomadores de decisões e pesquisadores.

O marco conceitual e teórico da EVIPNet busca maximizar a probabilidade de que a evidência obtida na investigação seja usada para configurar as normas e as práticas sanitárias.

\section{EVIPNET BRASIL}

O plano de desenvolvimento da EVIPNet Brasil é composto por seis etapas articuladas entre si:

Etapa I - Articulação da rede: articulação de parcerias para o desenvolvimento das ações previstas.

Etapa II - Discussão do Plano de Ação Anual: definição dos temas prioritários e detalhamento da metodologia para elaboração de policy brief (informe executivo de evidências), definição das atribuições e composição de grupos de trabalho para revisar a produção científica pertinente, sistematizar o conhecimento, cotejar os 
achados científicos com as questões apresentadas pela política nacional, conhecimento dos gestores e áreas técnicas, bem como elaborar os informes executivos.

Etapa III - Capacitação do(s) grupo(s) de trabalho: oficinas de capacitação sobre a metodologia da EVIPNet.

Etapa IV - Busca exaustiva da informação sobre os temas selecionados: revisão da produção científica nacional e internacional, além da sistematização do conhecimento dos gestores e das políticas nacionais sobre os temas e problemas definidos.

Etapa V - Elaboração e divulgação de informes executivos: nesta etapa, a partir das evidências encontradas e seu cotejamento com as políticas nacionais, serão elaborados os informes executivos, adequando-se a linguagem, conteúdo e formato para divulgação aos gestores.
Etapa VI - Fortalecimento da capacidade de utilização do conhecimento científico: desenvolvimento de atividades de capacitação de gestores, profissionais de saúde e membros do controle social para a recepção e análise crítica de informações científicas.

São parceiros nessa proposta: o Ministério da Saúde, a OPAS/Organização Mundial da Saúde (OMS), o Centro Latinoamericano e do Caribe de Informação em Ciências da Saúde (Bireme), a Fundação Oswaldo Cruz (Fiocruz), a Associação Brasileira de Pós-graduação em Saúde Coletiva (Abrasco), a Comissão Intersetorial de Ciência e Tecnologia do Conselho Nacional de Saúde, o Conselho Nacional de Secretários de Saúde (Conass) e o Conselho Nacional de Secretarias Municipais de Saúde (Conasems) e outros que ainda poderão se agregar durante o desenvolvimento do Projeto. 